\title{
Artificial Intelligence and the 2020 Municipal Elections in Brazil
}

\author{
Diego Santos Vieira de Jesus ${ }^{1}$ \& Adriane Figueirola Buarque de Holanda ${ }^{1}$ \\ ${ }^{1}$ Advertising and Propaganda, Higher School of Advertising and Marketing, Rio de Janeiro (ESPM-Rio), Brazil \\ Correspondence: Diego Santos Vieira de Jesus, Advertising and Propaganda, Higher School of Advertising and \\ Marketing, 90 - Centro, Rio de Janeiro - RJ, 20041-002, Brazil. Tel: 55-212-216-2002.
}

Received: June 6, 2020

Accepted: July 20, 2020

Online Published: August 2, 2020

doi:10.5430/ijba.v11n5p1

URL: https://doi.org/10.5430/ijba.v11n5p1

\begin{abstract}
The main purpose is to examine the possible role of artificial intelligence (AI) in the uncertain context of the 2020 municipal elections in Brazil. The central argument indicates that, regardless of when the elections are held, the COVID-19 pandemic opened spaces for candidates to build their political platforms on the initiatives to combat the disease, but also the opportunity for the dissemination of fake news and profiles regarding the spread of the new coronavirus and social distancing and quarantine measures with political purposes. The electoral discourse has increasingly used technologies and data such as voters' concerns, preferences, and oppositions, collected on social networks through AI. New data-based technologies can give rise to an unreal, induced, forged public opinion, in the same way that they can bring greater possibilities of discernment to the voter. The situation requires a more robust regulation for AI, but there are still many unregulated aspects and obstacles for the implementation of an effective regulation of online activities in Brazil, such as the poor adaptation of the legal space to highly volatile phenomena.
\end{abstract}

Keywords: artificial intelligence, municipal elections, Brazil, COVID-19, regulation

\section{Introduction}

The convergence of technological innovations on the physical, biological, and digital levels promises to change the ways people live and the way they work and consume. The Fourth Industrial Revolution has produced transformations in many societies, such as technologies and potential innovators, capable of promoting disruptions in relation to well-established procedures (Cyzmmeck, 2020). It combines numerous physical and digital technological innovations, including cyber-physical systems, artificial intelligence (AI), internet of things, computer clouds, adaptive robotics, and augmented reality. In the transport and logistics systems, the modernization may happen by the mass diffusion of unmanned vehicles. There will also be an increase in the complexity and precision in the manufacture of new construction materials due to the improvement of production technologies. These transformations occur in conjunction with the internet of things, which makes it possible to develop communications among machines and the self-management of physical objects, and the advance of AI, which allows the application of self-learning programs to provide constant system development of production. Such a revolution has been characterized by speed, which occurs in an exponential and not a linear rhythm, breadth, and depth. It is based on the digital revolution and combines several technologies that are leading to unprecedented paradigm shifts in the economy, business, society, and individual life (Barbosa et al., 2020).

AI can be also understood as the science and engineering of making intelligent machines and computer programs, which is related to the task of using computers to understand human intelligence, but not confining itself to biologically observable methods. One of the purposes of intelligent systems is to enable the computer to perform human functions based on the use of knowledge and reasoning. The examples of AI application range from the use of autonomous vehicles such as drones and autonomous cars to medical diagnosis, the creation of poetry and music, the proof of mathematical theorems, the generation of online assistants, the recognition of images and video, and online marketing (Novais \& Freitas, 2018). The use of AI for political purposes has been widely discussed in Brazil, especially because of its use in the spread of fake news in the 2018 elections for political propaganda. New skills are demanded of communication professionals, such as programming language, prototyping and product development. Some companies even needed to resort to other knowledge disciplines and the professionals that already worked with propaganda had to adapt to these new work characteristics (Schuch \& Petermann, 2020).

The focus of discussions for the 2020 municipal elections in Brazil seemed to be the COVID-19 pandemic, which 
radically changed the routine of societies around the world in a comprehensive and unexpected way. It forced an immense number of people to transform their habits at different levels: the professional routine, the hygiene and sociability habits and the redefinition of priorities (Cyzmmeck, 2020). The Brazilian federative system was confronted at its most vulnerable points by the pandemic, which seriously threatened the minimal functioning of public health services. Both the services and equipment under tripartite responsibility of federal, state, and municipal governments and those that are managed solely by states or municipalities, in the most immediate service to the population, have been shaken. Faced with a notorious public calamity, governors and mayors have used their political arsenal with different targets and interests. The search for federative cooperation at the subnational level was imposed on mayors and governors to fill the gaps left by the erratic and unstable federal management. The pandemic arrived in Brazil in the early 2020 and immediately threatened the municipal electoral process with the opening of "party windows". Uncertainty about party conventions and the beginning of the pre-election period was imposed. The campaigns that would take place in September and the elections in October were suspended. There is no doubt that the behavior of the mayors, the governors, and the president, when facing COVID-19, will be the main agenda in the debates (Carneiro \& Pitta, 2020). In the light of the chaotic scenario caused by the pandemic, a fertile space is generated for the spread of fake news that can directly interfere in the municipal electoral process, and AI may have a fundamental role in their dissemination.

The main purpose of this article is to examine the possible role of AI in the uncertain context of the 2020 municipal elections in Brazil. The central argument indicates that, regardless of when the elections are held, the COVID-19 pandemic opened spaces for candidates to build their political platforms on the initiatives to combat the disease, but also the opportunity for the dissemination of fake news and profiles regarding the spread of the new coronavirus and social distancing and quarantine measures with political purposes. The electoral discourse has increasingly used technologies and data such as voters' concerns, preferences, and oppositions, collected on social networks through AI. New data-based technologies can give rise to an unreal, induced, forged public opinion, in the same way that they can bring greater possibilities of discernment to the voter. Automated profiles can manipulate and disseminate rumors and defamation, requiring urgency in identifying the activities, intentions and authorship of these accounts, because they make it difficult for voters to differentiate the legitimate debate from the ones used to benefit or harm candidates. There is a strong possibility of an artificial, forged democracy being created in favor of a certain idea, political party, or religion, due to automated accounts and debates maximized by the action of robots. The situation requires a more robust regulation for $\mathrm{AI}$, but there are still many unregulated aspects and obstacles for the implementation of an effective regulation of online activities in Brazil, such as the poor adaptation of the legal space to highly volatile phenomena.

The originality of the article and its specific contribution to existing knowledge are related to the new possibilities of the use of $\mathrm{AI}$ in uncertain political contexts, especially when the motivations of the uncertainty are not only based on the political dynamics itself, but also the impact of external factors, such as a pandemic. Although previous studies (Hudson, 2019; Levy, 2018; Neff \& Nagy, 2016) have worked with the relations between AI and domestic and international politics, they did not deal precisely with the ways in which events outside the realm of politics may bring even more uncertainty to a society and impact the uses of $\mathrm{AI}$ in political processes, mainly elections. Besides dealing with these impacts, the article also works with a specific legal and political culture - the Brazilian culture -, which highlights the necessity of considering the particularities of the local context when analyzing the role of AI in elections.

\section{Method}

The article followed a logical and reflective structure, which emphasized interpretation and argumentation (Severino, 2000). After exposing the general developments regarding the Fourth Industrial Revolution and the need to regulate some aspects of the innovations brought by this revolution, it highlighted the specific situation of the uncertainties regarding the 2020 municipal elections in Brazil. The methodology addresses the analysis of recent texts about the situation of the electoral process and the regulation of new technologies and online activities - particularly AI - in the country.

Items identified as corresponding to the context of the 2020 municipal elections, the regulation of online activities and perspectives for the AI use in the Brazilian municipal elections in 2020 were examined in the bibliographic research carried out in recent works, which allowed a reflection through an approach in which characteristics present in the exposed context were analyzed and eventually linked to actions of the players in the legal and the political fields in Brazil. 


\section{Results}

\subsection{The Fourth Industrial Revolution and the Role of AI}

The speed of social and production changes brings challenges to the Legislative branch, which faces increasing difficulties to keep up with these transformations. The Legislative Houses have internal structures capable of keeping the study of technological innovation open, as well as the debate with the various sectors of civil society and market agents. Existing parliamentary commissions and fronts can be interesting avenues for dialogue. However, it is necessary to increase the attention of these bodies on the subject, to qualify and accelerate this debate. In Brazil, the Civil Rights Framework for the Internet and the General Data Protection Law are relatively recent examples of rules in which dialogue was essential to qualify the result of legislative work. Only the broad dialogue guarantees democratic and effective legislation in its day-to-day application. However, the difficulty of obtaining consensus and the alteration of the texts in process often end up resulting in generic laws and endless gaps (Domingues, 2020).

Unregulated situations and the existence of doubts and omissions persist. Conflicting practical situations arising from the application of the law will arise within the scope of public power in its relationship with private entities, as well as the interactions among economic agents and citizens and / or consumers. Until a uniform interpretation of the law occurs, the conduct that is practiced in the virtual environment is interpreted within a legislation that only provided for conduct existing in the physical world. For example, the undue exposure of people's privacy, attacks on bank accounts in the internet and the hacking of computer data by people or companies needed to be framed in the conduct regulated by the traditional legislation, until specific laws on online crimes were approved (Domingues, 2020).

The so-called "Industry 4.0 " brings a series of regulatory dilemmas, such as those related to "big data", which initially referred to extensive data sets in processes centered on the entry of scientific investigation records. In 2003, projects developed at the University of Washington pointed to business initiatives at different institutions to deal with large volumes of data, and multiple types of activities and businesses were strongly impacted. Big data is directly associated with the amount of data, the set of sources and sources, the agile and frequent way they are generated and consumed, the credibility of the used data, and the ability to generate quantifiable benefits for users. Since the early $2000 \mathrm{~s}$, the debate about the procedures and technologies for the capture, analysis, treatment, storage, and dissemination of these volumes of information has been expanded. The informational explosion led people to realize their limited ability to analyse different data sources through the evolution of technological devices and the internet itself, with the agile processing of data and cloud computing (Ribeiro, 2020).

Another aspect of the Industry 4.0 that stimulated debates was the "internet of things", which refers to an environment of physical objects interconnected with the internet and creates an omnipresent computing ecosystem to facilitate and bring solutions to today's challenges. Computers, sensors, and objects interact with each other and process information and data in a context of hyperconnectivity. Things connect to the internet with the ability to share, process, store and analyse a huge amount of data. This practice links the internet of things to big data. However, data from various interconnected devices, generated spontaneously and deliberately by users, may pose risks to the users' constitutional rights, such as privacy and security, and may expose them to losses of which they are not yet fully aware. In addition to the individual care, care is also needed in the action of the legislator, who must protect users' rights while opening spaces for economic and technological development (Magrani \& Oliveira, 2020).

One of the constituent elements of Industry 4.0 is AI, used in industrial and mechanical processes, the provision of services and virtual social relationships. AI has traditionally focused on the development of automated solutions by systems or agents for problems that would require the intervention of intelligence if executed by humans (Negnevitsky, 2004). AI typically referred to cognitive functions associated with the human mind, such as problem solving and learning, so that machine learning would become a prerequisite for the AI development (Carbonell et al., 1983). However, more recent definitions point out that AI refers to the ability of a system to correctly interpret external data, learn from that data and use learning to achieve specific goals and tasks through flexible adaptation. In the contemporary world, a defining element of AI systems is the multiplicity of ways in which machines learn from past information. Three types of primary learning processes can be identified: supervised, non-supervised and reinforced learning. The first maps a set of inputs to a given set of results, including methods such as linear regression, classification trees and neural networks. In the second, the inputs are labeled, but the results are not, which means that the algorithm needs to infer the underlying structure of the data itself, as in cluster analysis that aims to group elements in similar categories, but in which neither the structure of clusters nor their number are known in advance. In reinforced learning, the system receives a variable result to be maximized and a series of decisions that can be made to impact it. From the identification of contemporary learning processes, it is possible to identify three central AI uses: data organization, aid to decision making and decision automation (Kaplan \& Haenlein, 
2019).

However, there are problems that need to be addressed when dealing with the AI central uses, especially in contexts that require human judgment and analysis to solve problems with guaranteed success. Such decision-making situations are often related to strategic issues in companies and governments, in which the problems are far from well-structured (Martínez-López \& Casillas, 2013). AI has implications for the lives of people and communities and sparks the debate about how far legislation should go, without encroaching on the freedom of people and economic agents or hampering the capacity for innovation. The discussion includes the question of whether the algorithms used in decision-making are subject to standardization. One of the main issues is whether the neutrality of the algorithms can be determined by law and who would oversee the inspection of the neutrality. The state, for example, can control the location of individuals by cell phone or by simply moving down the street. In some countries, such control may have positive effects on citizens, proportional to their adherence to legal rules, as a criterion for facilitating access to public services and benefits. In the private sector, access by companies to almost all personal data and their commercialization is a reality. However, it is worth questioning whether the brakes established by data protection laws would be successful or what the prospects for success would be, in practice, of national or international regulation that would prevent the violations of data protection guidelines and their use by companies or governments. On the one hand, such regulations could help stem the spread of cyberattacks, which daily expose and slander people, destroy reputations, spread fake news and influence minds and elections with the mass firing of messages through social networks and communication applications. On the other hand, one can question the ways to prevent and suppress these behaviours efficiently (Domingues, 2020).

Most debates about the AI regulation are based on the fact that intelligent agents might operate without the intervention of other agents and have control over their actions and state of internal knowledge, perceive what happens in their universe of discourse and respond appropriately and in a timely manner to changes in their environment. They can also be proactive, because they can take initiatives and conduct their own actions according to objective-driven behavior. Such agents interact with other agents and communicate with them, competing or cooperating in solving problems. Some agents can develop their own conscience and present characteristics such as perceptibility, sentimentality, and emotion. They can perform tasks and not only fulfil but define goals and strategies to achieve them. These agents can learn and acquire knowledge from the assimilation of behavior patterns or preferences expressed by the agents themselves. Most of all, intelligent agents can be autonomous, which means they can act based on their own decision rules, with no need to be guided by humans (Novais \& Freitas, 2018).

In the case of electoral disputes, the AI regulation debate is even more fundamental. In the Brazilian case, the jurisprudence regarding the promotion of content on the internet, whether through websites, messaging applications or social networks, is recent. Before a 2017 legislative change that allowed the dissemination of messages, candidates were condemned for this practice, characterized as "illegal propaganda". However, in other cases, driving negative messages to opposing candidates was considered an exercise of the freedom of expression, considering that there was still no legislative provision for driving content on the internet during election campaigns. Candidates bet on electoral propaganda to convince the voter and form an opinion about their government platforms. The electoral discourse has increasingly allied itself with technologies and started to use data such as voters' concerns, preferences, and oppositions, collected on social networks through AI. New data-based technologies, with data provided by the users themselves, can give rise to an unreal, induced, forged public opinion, in the same way that they can bring greater possibilities of discernment to the voter. Automated profiles can manipulate and disseminate rumors and defamation, requiring urgency in identifying the activities, intentions and authorship of these accounts, because they make it difficult for voters to differentiate the legitimate debate from the ones used to benefit or harm candidates. Although the Brazilian legislation provides for the possibility for candidates to hire service providers to promote paid content in electoral advertising, there are many technological aspects to be unveiled, especially regarding the influence of the content in the formation of the voter's convictions and choices. Among them, it is worth highlighting the algorithms, conceptualized as a logical, finite, and defined sequence of instructions that must be followed to solve a problem or perform a task. The algorithms, the result of artificial intelligence, use data and programming to achieve a specific purpose. Thus, algorithms can start making decisions and guide political decisions and actions that were previously taken by humans (Leal \& Moraes Filho, 2019).

\subsection{The Context of the 2020 Municipal Elections}

The Brazilian president Jair Bolsonaro is the first leader of the current democratic period not to be affiliated with a party with candidates able to run for municipal elections. However, the use of his power to define the agenda of the national debate allows the competitors to seek for an association with the ideological flags defended by Bolsonaro. 
This hypothesis is reinforced by Bolsonaro's approximation with politicians from the bloc called "the big center" ("centrão" in Portuguese), formed by parliamentarians with electoral strongholds generally well-defined and interested in guaranteeing the transfer of funds to allied mayors, through parliamentary amendments and the occupation of positions in the administration (Carneiro \& Pitta, 2020).

Some parties that had the greatest number of elected mayors in the 2016 elections were shaken by 2020 , worn out by the implications of Lava Jato Operation, which investigated money deviations in the national oil company Petrobras, shook the political force of the Workers' Party (PT, its acronym in Portuguese) and culminated in the impeachment of president Dilma Rousseff and the reduction of the party's participation in municipal administrations. In the field identified as progressive and antagonistic to the conservatism represented by Bolsonaro, the PT seeks ways to recover part of the political capital lost in 2016. When it managed to reach the second round against Bolsonaro with the candidacy of the former mayor of São Paulo Fernando Haddad in the 2018 presidential elections and elect the second largest group of federal congressmen, the party remained the main reference of its ideological spectrum, but saw the advance of other political parties, such as PSOL and PDT, in the opposition to the federal government (Carneiro \& Pitta, 2020).

The 2018 elections were characterized by the intense involvement of voters in social networks, so that the internet has become a new field for electoral activities within the scope of campaigns. The need for new rules and greater control of candidates' attitudes in the virtual environment were evident, as well as questions about the limits of the virtual campaign, the period when it could start, what content would be allowed and how it could be presented. According to the Brazilian law, the participation of members of political parties or pre-candidates in interviews, programs, meetings or debates on radio, television and the internet does not constitute propaganda in advance, including the presentation of political platforms and projects. The Brazilian Superior Electoral Court has confirmed that, as private internet providers, as well as main transmission channels, Google, Facebook, and YouTube are not required to give equal time or opportunities for appearances among candidates. It is also allowed that, even before August 15th, the legal beginning of the campaigns, internet channels broadcast the holding of party previews and the respective distribution of informative material, as well as the disclosure of the names of the members who will participate in the dispute, the holding of debates among pre-candidates and the disclosure of personal positions on political issues, including on social networks, privileging interpretation according to the free expression of thought. It is also argued that it would not be reasonable to control the diffuse manifestations that occur through social networks and instant messaging applications (Almeida \& Guaraty, 2020).

A candidate's website is legal as a form of propaganda on the internet, with an electronic address communicated to the Electoral Court and hosted, directly or indirectly, by an internet service provider established in Brazil, as well as the party or coalition website, with an electronic address communicated to the Electoral Court and hosted, directly or indirectly, by an internet service provider established in the country; electronic messages to registered addresses free of charge by the candidate, party or coalition; blogs, social networks, instant messaging sites and similar internet applications whose content is generated or edited by candidates, parties or coalitions; or any natural person, as long as they do not hire content promotion. The payment for the placement of electoral propaganda on the internet with no legal permissions is also prohibited, as well as the anonymity of fakes or the attribution of advertising to a third party, including a candidate, party or coalition; the hiring of virtual activists, "robots" or fakes to issue offenses or denigrate the image of a candidate, party or coalition; the placement of electoral propaganda on pages of legal entities or websites hosted by agencies or entities of the direct or indirect public administration; and the sending of mass messages (spam), telemarketing or the purchase of a database of records of electronic addresses, telephones or personal profiles for sending electoral propaganda. From the 2018 elections on, it became legal to drive publications if the budget application is made by the candidate, party, or coalition, and hiring through a natural person or a third party is prohibited. The hiring of the driving of messages must be done directly by the candidate, party, or coalition. Voters cannot drive the content of their candidates, who must inform as much as possible about this prohibition. The driving of messages will be the exclusive form of electoral propaganda paid on the internet, and the unequivocal identification and contracting exclusively by parties, coalitions and candidates and their representatives are also required. In addition, the driving of messages should be done through a personal profile, and the use of a "sponsored page" is prohibited (Almeida \& Guaraty, 2020).

In 2020, the measures to combat the COVID-19 pandemic were taken mainly by the subnational governments, with no coordinated national strategy, due to the difficulties and complexities of facing a pandemic little known to science and the cyclical tension of Brazilian politics. The public opposition, the resistance of the president to respect the measures taken by governors, mayors, and the Ministry of Health, which underwent two changes of leadership in less than a month, stand out. Whether through a purposeful agenda of regional initiatives or the federative 
confrontation, the pandemic has highlighted the importance of the political and administrative pact among the three spheres of government. The municipal units, which are closer to the citizens, seem to be working more effectively as sounding boards for the communities' priority needs. The mayors and their secretaries find out that, by acting in the search of unity at the regional level, it is easier to find more appropriate solutions to common problems. Whatever the date set by the National Congress for the municipal elections, the COVID-19 pandemic and its socioeconomic consequences are unlikely to be left out of consideration for voters. The responses given by the local managers, combined with the actions taken by the state and federal governments, to face the pandemic will be an unprecedented and decisive variable for the outcome of the next municipal elections (Carneiro \& Pitta, 2020). However, it also opens spaces for candidates to build their political platforms on the struggle against COVID-19, as well as the dissemination of fake news and profiles regarding the dissemination of the disease and social distancing and quarantine measures with political purposes. AI may have an important role in this process, which highlights the need for its robust regulation. However, there are still many obstacles for the implementation of an effective regulation of online activities - especially those related to AI - in Brazil.

\subsection{The Regulation of Online Activities in Brazil}

The regulation of online activities had as one of its most important actions the 2001 edition of Provisional Measure 2200-2, which created the Brazilian Public Key Infrastructure. The measure sought to regulate electronic transactions and give the parties the necessary legal certainty, through a digital certificate that would allow them to be sure of the authorship, content, and authenticity of an electronic document. More recently, the Law 12.965 / 2014, known as the Civil Rights Framework for the Internet, sought to bring legal certainty by establishing, for example, the civil liability of internet application providers, when, summoned by court order to remove third party content, do not implement the decision. However, it does not seem enough to fulfil the purpose. There are no specific penalties for the company, and the instruments of coercion to comply with decisions do not seem to be effective so far, such as the cases of temporary blocking of Facebook or WhatsApp as a way to stop the repeated breach of court orders to withdraw content or request information. These blocks would be effective for solving the issue in the specific case, but with the side effects of impairing the personal and professional uses of these tools by millions of people. These are issues that are still the subject of heated debates and have not been adequately resolved, in law and jurisprudence, in Brazil (Domingues, 2020).

The Law 13.709 / 2018, the General Data Protection Law, is a relevant legal framework for the protection of citizens in their daily and digital lives and an expression of an individual right that points to data as personal and not as something that companies can take and use with no limits. The law establishes clear principles for the treatment of people's data, such as transparency; the use of technical and administrative measures to protect personal data from unauthorized access and accidental or unlawful situations of destruction, loss, alteration, communication or dissemination; the adoption of measures to prevent the occurrence of damages due to the processing of personal data; the condemnation of illicit or abusive discriminatory purposes; and the demonstration, by the agent, of the adoption of effective measures capable of proving the observance and compliance with the rules of protection of personal data and the effectiveness of these measures. The General Data Protection Law alters companies' compliance procedures and the form of relationships with the people whose data is collected. Responsibility reaches sectors such as digital marketing, communications, education, and the internet of things. It is relevant to highlight the bill 21/2020, which is still in process and establishes principles, rights, and duties for the use of AI in Brazil. It was attached to the bill a project which establishes an AI law in the country. The initiative provides for the neutrality of the algorithms to be used by systems and robots in industry and establishes the adoption of several statements and principles contained in the OECD Declaration of Principles for Artificial Intelligence, adopted in May 2019 and signed by Brazil (Domingues, 2020).

The bill indicates that the use of AI will be based on the respect for human rights and democratic values, equality, non-discrimination, plurality, free initiative, and data privacy. The author of the project, the congressman Eduardo Bismarck, said that the aim was to provide the country with legislation that, at the same time, stimulates AI and protects citizens from its misuse. Bismarck's text indicates the role of the AI agent, who can be both the person who develops and implements an AI system (the development agent), as well as the one who operates (the operating agent). AI agents will have duties, such as responding legally to decisions made by an AI system and ensuring that the used data respects the General Data Protection Law. The bill also provides for the rights of AI agents and all persons affected by AI systems (referred to as "interested parties"). Among them, it is worth mentioning the access to the way in which systems use sensitive personal data, such as genetic data. There is also the proposal of the creation of the AI impact report, a document prepared by the AI agents with a description of the technology, including risk management and containment measures. The publication of the report may be requested by the government, which 
may also recommend the adoption of standards and improvements. The text also encourages the government to adopt $\mathrm{AI}$ in public services, preferably in an open and free format, support research in the area, train workers to adapt to the new technological reality, and create governance mechanisms (Junior, 2020). However, the bill was still under discussion in the time of the writing of this article.

\section{Discussion}

In Brazil, the electoral propaganda is governed by the Election Law and seeks to garner support and, above all, votes. The Law 13.487 changed the Law on Elections and the Law on Political Parties and extinguished Party Advertising on Radio and Television, thus reducing the visibility of political parties in the so-called mainstream media. On television and radio, paid political propaganda is prohibited, under the penalty of a fine. However, on the internet, it can be paid, including the possibility of driving the content. The promotion of content in the electoral campaign on the internet is compatible with the evolution of technologies and aims to expand the candidates' possibilities of reaching the voter. Thus, internet campaigns have gained prominence and become important tools in winning the vote. Political campaigns on social networks, for example, have become as or more important than the propaganda shown on radio and television. However, the problem is the lack of transparency of the algorithms because it is not typically known which personal data are collected, what criteria are used in the collection and how they are being used. On the social media, robots are used to spread fake news or even create an artificial debate. The most modern algorithms can identify popular profiles and follow them, as well as write a short text and interact (Leal \& Moraes Filho, 2019).

The debate on the use of social media in elections has been frequent. In the United States, the 2016 elections showed that social media, such as Twitter and Facebook were platforms used to engage voters. Many of them were engaged by fake news, which led Donald Trump to win. In Brazil, during the 2018 elections, these social media platforms had significant spaces, but the protagonist was WhatsApp, an instant messaging application. WhatsApp was mainly used by supporters of then candidate Jair Bolsonaro to spread fake news. According to Santos et al. (2019), the successful appropriation of WhatsApp by Jair Bolsonaro's results from the cooperation of several groups and a specific knowledge aimed at the systematic dissemination of content.

Digital platforms create potential for more communication, thus enabling the discussion of innumerable issues, such as the affections to democracy in discussion forums, social networks, and messaging applications. The answer to questions about the possible increase or decrease in voters' discernment due to the large amount of information and, above all, due to the algorithms built to actively influence voters is still unknown. Regardless of the analysis about the robots, the collected personal data and the criteria and forms in which they are being used for each situation are not informed with transparency. The concern falls on the possibility of an artificial, forged democracy being created in favor of a certain idea, political party, or religion, due to automated accounts and debates maximized by the action of robots (Leal \& Moraes Filho, 2019).

The electoral law prevents the use of degrading means for the purpose of an election campaign, such as trickery, montage or other audio or video resources that, in any way, ridicule a candidate, party or coalition. The use of "low-profile" propaganda is a way to negatively affect the candidates' image, considered by the legislator as harmful to the democratic process of choice. In the 2018 Brazilian presidential elections, it became apparent that the media power of the slanderous exposure of candidates became extreme with the use of social networks, especially with the use of AI tools. Such an effect, combined with political polarization, the popularity of social networks and the reduction in costs of online propaganda, made the fertile ground for the spread of fake news. Viewed from a legal point of view, the threat to the principle of the veracity of propaganda forced a response from the electoral system. The parallel with crimes against honor was then reinforced with the advent of Law 13834 / 2019, which created the criminal classification of slanderous denunciation for electoral purposes, understood in the context of the worldwide phenomenon of fake news in a forceful way. The dissemination of fake news will be penalized when any potential crime that the candidate has committed is claimed, when he/she knows that the news is fake. If the falsehood is reported and generates an investigation or prosecution, the person who disseminated the fake news will be committing a crime. The application of the article, however, is still somewhat uncertain, since the courts will have the opportunity to judge it for the first time in the 2020 elections. The resolution 23.551 of the Superior Electoral Court brought a more detailed treatment of the problem. The free expression of the thought of the identified or identifiable voter on the internet is only subject to limitation when there is an offense against the honor of third parties or the disclosure of facts known to be untrue. Facts known to be untrue should limit the voter's subjective right to express his/her criticism, opinions, and information about candidates. The doctrine already suggests possibilities of including in the prohibition the use of montages, images, videos, or any other type of manipulated 
content that has the purpose of disseminating information known to be untrue. Although it is common for fraudulent facts to be reported by people who sincerely believe the fake news, they could not be held responsible. Fake news many of which are triggered by AI tools - will be a major challenge for Electoral Justice. There is a conflict inherent in all regulation of ideas that are the democratic and necessary stimulus for debate at the electoral level, but also a harmful way of compromising the will of the voter (Almeida \& Guaraty, 2020).

\section{Final Considerations}

Once the government, companies and universities organize themselves in projects aimed at the AI development, political and legal dilemmas on a number of issues could need constant monitoring, such as contractual rights and responsibilities, rights related to patents, licenses, publishing rights and proprietary information, academic conflicts of interest and involvement of foreigners in projects that are relevant to national security, for example (Muspratt, 1986; Leydesdorff \& Etzkowitz, 1998). Although working with the particularties of the Brazilian context is fundamental to understanding the relations between AI and politics in this article, it is possible to derive from the Brazilian case, go beyond the local discussion and show the main AI general implications for practice and further research. AI has implications for countless social institutions. Internally, these systems allowed a broad set of tasks to be conducted more quickly, better and at lower cost. Externally, they impacted the relationship of these institutions with companies, consumers, governments, and society. Within these institutions, managers need to adapt their leadership style and reinforce the confidence of their employees in an environment in constant transformation. Employees will need to constantly adapt their roles and skills through a continuous learning process, and machines need to be monitored to avoid autonomous decisions that have negative legal and ethical implications. Externally, users should be encouraged to have more confidence in the skills and recommendations of an organization's AI systems. In an even broader context, governments will need to create more specific rules and standards for the functioning of the ecosystem of managers, employees, machines, users, and competitors, including political competitors in elections (Kaplan \& Haenlein, 2019). Among the short-term research priorities for a more robust AI use, it is worth highlighting the optimization of its economic impact, the development of labor-intensive sectors, and the use of the wealth generated by AI to support unemployed and underemployed people. These priorities would bring to the debate the need for interventions, such as educational reforms, the development of apprenticeship programs and changes in laws regarding the minimum wage, tariff structure and social security. The debate on legal and political issues would be a priority. It is necessary to develop cyber law to cover the increasingly diverse political and commercial AI applications (Russell et al., 2015).

In the Brazilian case, the seriousness of the COVID-19 pandemic exposed the weakness of the federal system and public administrations at the three levels of government in Brazil. It is expected that, given the dire situation, structural issues such as political and tax reforms and the modernization of Brazilian public management can be placed on the political agenda (Carneiro \& Pitta, 2020). Regarding the AI, the creation of legal norms, their interpretation and application require the legislator and interpreter their own time so that they do not give in to untimely impulses. For this reason, the "legal" space is poorly adapted to highly volatile phenomena, such as AI. The speed with which the emergence and forgetfulness of technologies is seen means that the legislators, when compelled to regulate a certain sector, experience difficulties at various levels. Since the new technologies have underlying sciences with lexicons completely different from those used in law, the question arises of how to standardize a reality that is ontologically extra-legal. Judicial operators, prepared almost exclusively for the tasks of reading and interpreting the law, do not have the technical and academic skills to understand the horizon that each of the technical terms related to new technologies implies in practical life. However, the dizzying advance of AI should not prevent people from taking an active role in shaping the AI development. A starting point may be the creation of a Brazilian Agency for Robotics and Artificial Intelligence, with powers of consultancy, supervision and regulation, whose composition reflects the multidisciplinarity and complexity of the issue (Novais \& Freitas, 2018).

\section{References}

Almeida, R. R., \& Guaraty, K. D. (2020). As mudanças na lei eleitoral para 2020, incluindo a biometria. Cadernos Adenauer, XXI(2), 57-77.

Barbosa, A., Costa, J., \& Pontes, R. (2020). Cidades Inteligentes no contexto da quarta revolução industrial. Cadernos Adenauer, XXI(1), 9-33.

Carbonell, J. G., Michalski, R., \& Mitchell, T. (1983). Machine learning: an artificial intelligence approach. Berlin: Springer. https://doi.org/10.1007/978-3-662-12405-5

Carneiro, J. M. B., \& Pitta, I. (2020). Eleições municipais e COVID-19: a conjuntura política antes e depois da chegada do coronavírus no Brasil. Cadernos Adenauer, XXI(2), 11-28. 
Czymmeck, A. (2020). Apresentação. Cadernos Adenauer, XXI(1), 7-8.

Domingues, J. S. (2020). Legislativo 4.0: O desafio da criação de novas leis para um mundo em mutação. Cadernos Adenauer, XXI(1), 35-58.

Hudson, V. (2019). Artificial intelligence and international politics. New York: Routledge. https://doi.org/10.4324/9780429033575

Junior, J. (2020). Projeto cria marco legal para uso de inteligência artificial no Brasil. Agência Câmara de Notícias. $\begin{array}{llll}\text { Retrieved June } & 14, & 2020, & \text { from }\end{array}$ https:/www.camara.leg.br/noticias/641927-projeto-cria-marco-legal-para-uso-de-inteligencia-artificial-no-brasil/

Kaplan, A., \& Haenlein, M. (2019). Siri, Siri, in my hand: Who's the fairest in the land? On the interpretations, illustrations, and implications of artificial intelligence. Business Horizons, 62(1), 15-25. https://doi.org/10.1016/j.bushor.2018.08.004

Leal, L. F. S., \& Moraes Filho, J. F. (2019). Inteligência artificial e democracia: os algoritmos podem influenciar uma campanha eleitoral? Uma análise do julgamento sobre o impulsionamento de propaganda eleitoral na internet do Tribunal Superior Eleitoral. Direitos Fundamentais \& Justiça, 13(41), 343-356. https://doi.org/10.30899/dfj.v13i41.793

Levy, F. (2018). Computers and populism: artificial intelligence, jobs, and politics in the near term. Oxford Review of Economic Policy, 34(3), 393-417. https://doi.org/10.1093/oxrep/gry004

Leydesdorff, L., \& Etzkowitz, H. (1998). The Triple Helix as a Model for Innovation Studies. Science \& Public Policy, 25(3), 195-203.

Magrani, E., \& Oliveira, R. M. (2020). An Internet das Coisas e a Lei Geral de Proteção de Dados: reflexões sobre os desafios do consentimento e do direito à explicação. Cadernos Adenauer, XXI(1), 123-142.

Martínez-López, F. J., \& Casillas, J. (2013). Artificial intelligence-based systems applied in industrial marketing: An historical overview, current and future insights. Industrial Marketing Management, 42, 489-495. https://doi.org/10.1016/j.indmarman.2013.03.001

Muspratt, M. A. (1986). Artificial intelligence. Journal of Professional Issues in Engineering, 112(3), $158-169$. https://doi.org/10.1061/(ASCE)1052-3928(1986)112:3(158)

Neff, G., \& Nagy, P. (2016). Talking to Bots: Symbiotic Agency and the Case of Tay. International Journal of Communication, 10, 4915-4931.

Negnevitsky, M. (2004). Artificial intelligence: A guide to intelligent systems. Harlow: Addison-Wesley.

Novais, P., \& Freitas, P. M. (2018). Inteligência Artificial e regulação de algoritmos. Brasília: Ministério da Ciência, Tecnologia, Inovações e Comunicações.

Ribeiro, C. J. S. (2020). Big data no contexto da quarta revolução industrial: transformações no processo de Pesquisa e Desenvolvimento (P\&D). Cadernos Adenauer, XXI(1), 93-110.

Russell, S., Dewey, D., \& Tegmark, M. (2015). Research Priorities for Robust and Beneficial Artificial Intelligence. AI Magazine, 36(4), 105-114. https://doi.org/10.1609/aimag.v36i4.2577

Santos, J. G., Freitas, M., Aldé A., Santos, K., \& Cunha, V. C. C. (2019). WhatsApp, política mobile e desinformação: a hidra nas eleições presidenciais de 2018 . C\&S, $41(2), \quad 307-334$. https://doi.org/10.15603/2175-7755/cs.v41n2p307-334

Schuch, L. A., \& Petermann, J. (2020). Algoritmos e Big Data: processos de atualização no habitus publicitário. Signos do Consumo, 12(1), 14-26. https://doi.org/10.11606/issn.1984-5057.v12i1p14-26

Severino, A. J. (2000). Metodologia do trabalho científico. São Paulo: Cortez.

\section{Copyrights}

Copyright for this article is retained by the author(s), with first publication rights granted to the journal.

This is an open-access article distributed under the terms and conditions of the Creative Commons Attribution license (http://creativecommons.org/licenses/by/4.0/). 